\title{
A Case of Pachydermodactyly
}

\author{
Sang-Hee Seo, M.D., Hyun-Woo Sung, M.D. ${ }^{1}$ \\ Department of Dermatology and Medical Research Institute, Pusan National University Hospital, Yangsan, ${ }^{1}$ Department of Orthopedics, \\ Dong-A University Medical Center, Busan, Korea
}

Pachydermodactyly (PDD) is a rare, benign form of digital fibromatosis and this is characterized by asymptomatic soft tissue swelling that affects the lateral aspects of the proximal interphalangeal (PIP) joints of the fingers. Although the etiology of PDD is unknown, the possibility of repetitive minor trauma by habitual or compulsive habits of interlacing the fingers or rubbing of the fingers has been suggested as a cause by several authors. We experienced a 14-year-old boy who was diagnosed as having PDD by the clinical manifestations and this was supported by a radiological study and the routine laboratory tests. He also had the habit of repetitively manipulating his hands when feeling emotional distress. PDD sometimes can be misdiagnosed as a rheumatic condition. Although an unusual disorder, PDD should be considered in the differential diagnosis of patients who present with digital bulbous swelling. (Ann Dermatol 23(2) 258 261, 2011)

\section{-Keywords-}

Pachydermodactyly

\section{INTRODUCTION}

Pachydermodactyly (PDD), from the Greek words pachy (thick), dermo (skin) and dactylos (finger), was first reported by Bazex et al. ${ }^{1}$ in 1973. PDD is benign, asymptomatic soft tissue swelling that affects the skin on the lateral aspects of the proximal interphalangeal (PIP) joints of fingers II $\sim \mathrm{IV}$; this condition mostly occurs in adolescent males and it could be interpreted as a consequence of

Received February 23, 2010, Revised July 14, 2010, Accepted for publication July 14, 2010

Corresponding author: Sang-Hee Seo, M.D., Department of Dermatology, Yangsan Pusan National University Hospital, Beomeo-ri, Mulgeum-eup, Yangsan 626-770, Korea. Tel: 82-55-360-1674, Fax: 82-55-360-1679, E-mail: soesh97@daum.net tic-like behavior due to obsessive-compulsive disorder in male adolescents. Only approximately 88 cases of pachydermodactyly have been reported worldwide ${ }^{2}$.

\section{CASE REPORT}

A 14-year-old boy presented with asymptomatic, progressive, symmetrical thickening of the soft tissue around the PIP joints of both hands since the age of 4 years. He did not have morning stiffness, fever, rashes, mouth ulcer, uveitis or gastrointestinal symptoms. He manipulated his hand repeatedly during the medical consultation. He had been treated in the psychology department because of emotional distress, but the other parts of his medical history were unremarkable. His family history was noncontributory. Physical examination revealed bilateral symmetric soft tissue swelling on the PIP joints of the second through the fourth fingers, with slight epidermal thickening (Fig. 1). The patient was asymptomatic; in particular, he had no pruritus, burning or pain on his hands. There were no joint effusions, and the range of motion was within the normal range. No other joints were affected. No other changes in the skin or nails were observed. The results of laboratory investigations, including a complete blood count, liver/renal function tests, a thyroid stimulating hormone test, urinalysis and assessing the erythrocyte sedimentation rate, C-reactive protein, rheumatoid factor and antinuclear antibody, were within the normal range or negative. The result of the human leukocyte antigen B27 test was negative. Radiography of the hands revealed soft tissue swelling without joint space narrowing, bony erosions or other structural abnormalities. A bone scan did not show any abnormal uptake in the joints of the body. Histopathologic analysis revealed hyperorthokeratosis, acanthosis, thickening of the dermis with irregular bundles of thickened collagen and small deposits of mucin (Fig. 2). The patient was diagnosed with PDD, and intralesional triamcinolone 


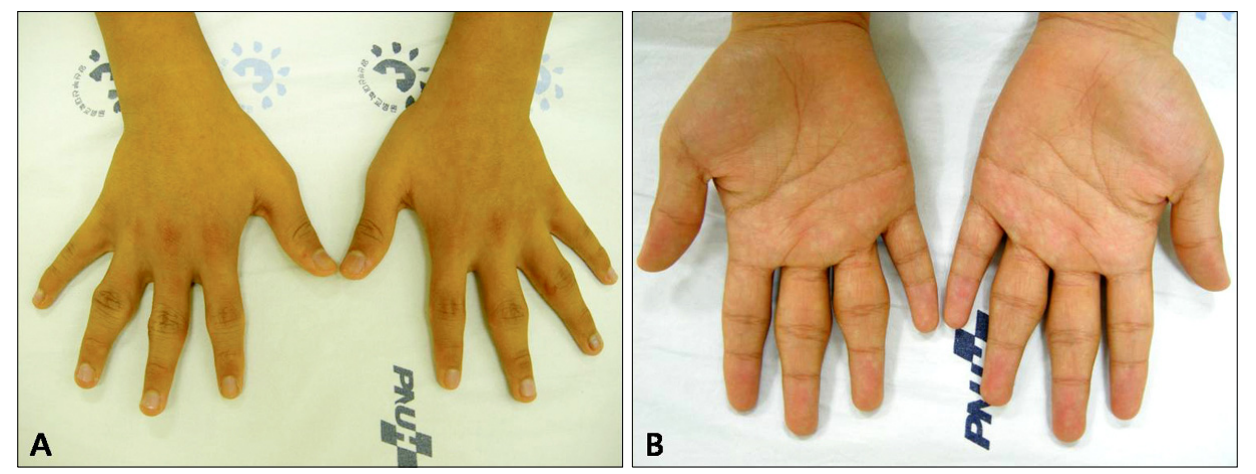

Fig. 1. Bilateral symmetric soft-tissue swelling on the proximal interphalangeal joint of the second through fourth fingers with thickening of the skin. The frontal side view (A) and the back side view (B).
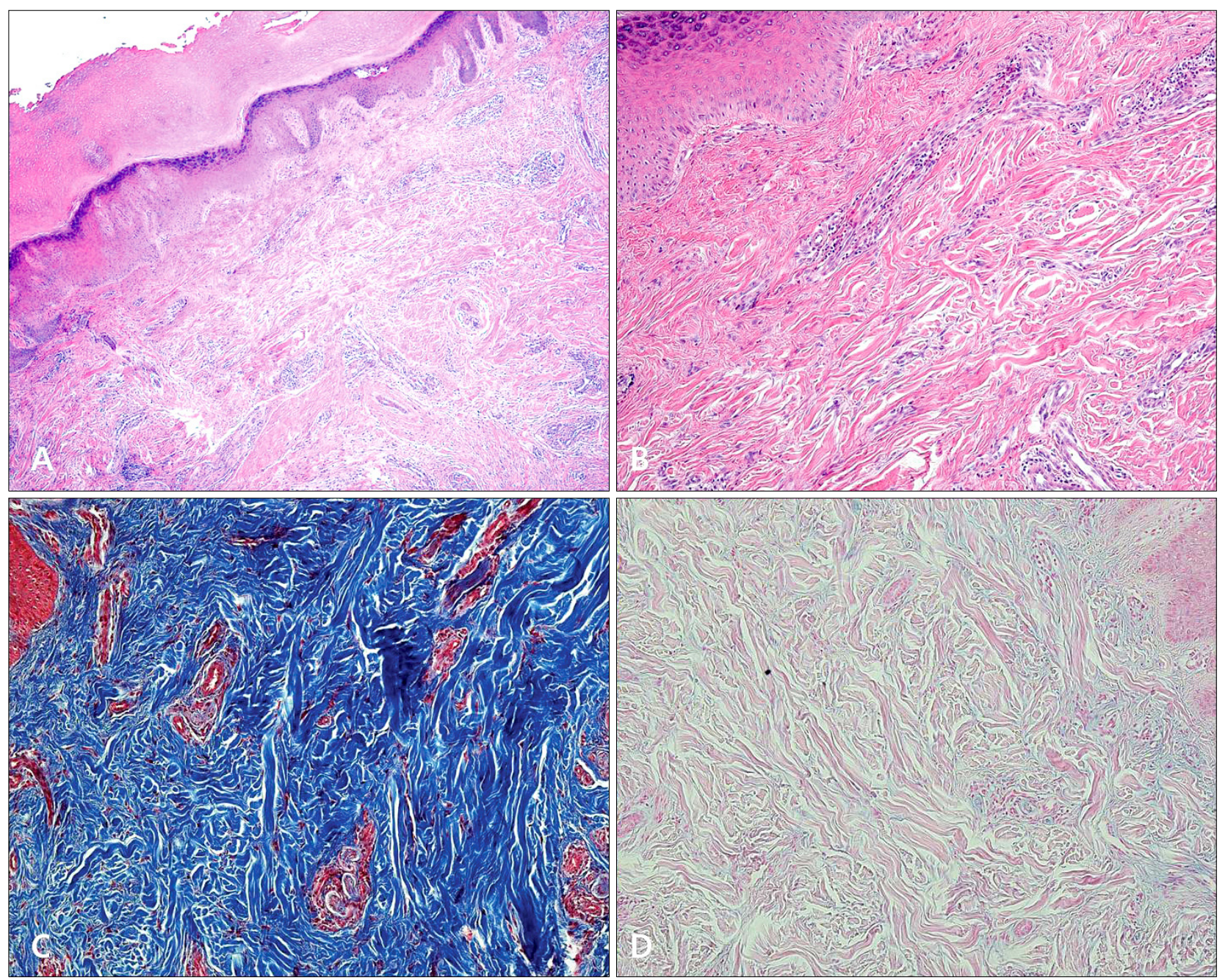

Fig. 2. (A) Hyperorthokeratosis, acanthosis and thickened dermis (H\&E stain, $\times 40)$. (B) Irregular bundles of thickened collagen $(H \& E$ stain, $\times 100$ ). (C) Irregular bundles of thickened collagen (Masson-Trichrome stain, $\times 100$ ). (D) A small deposit of mucin (Alcian blue stain, $\times 100$ ).

injection or localized subcutaneous resection was recommended. However, the patient refused treatment because of the benign characteristics of the disease. He was advised to stop inducing any mechanical skin irritation to his fingers.

\section{DISCUSSION}

PDD has been recognized as a distinct clinical entity because of its typical presentation of asymptomatic swelling of the periarticular soft tissues over the PIP joints 
without any fundamental damage to the joint structures. PDD usually affects otherwise healthy young individuals (mean age: 21.2 years, male/female ratio: $3 / 2)^{2}$. The evolution of joint swelling is insidious; it seems to be more prone to symmetrical development, but it is often predominant in 1 or a few joints ${ }^{3}$. Our patient was a 14-year-old boy who showed asymptomatic, progressive, symmetrical involvement around the PIP joints of both hands. The distal interphalangeal joints and other joints are usually not affected. PDD has occasionally been reported to involve the more proximal metacarpal phalangeal joints or the palm or dorsum of the hand ${ }^{4}$. In these cases, the condition has been termed as pachydermodactyly transgrediens.

The diagnosis of PDD is clinical and it is supported by radiological studies and routine laboratory investigations ${ }^{5}$. According to other authors, a histopathologic examination is not necessary for making the diagnosis. Radiography, bone scintigraphy, ultrasonography and magnetic resonance imaging reveal soft tissue swelling with no bone or articular abnormalities ${ }^{5}$. The laboratory picture is noninflammatory and autoantibodies are absent. Histopathologic examination reveals an increase in dermal collagen with variable degrees of overlying hyperkeratosis and acanthosis ${ }^{2}$. Mucin stains of skin biopsy specimens may reveal increased dermal mucin deposits. Some authors have reported eccrine gland entrapment and occasional vascular and fibroblast proliferation ${ }^{6}$. Collagen isolated from the involved sites shows a structure consistent with that of collagen types III and V; this differs from the collagen profile of normal skin ${ }^{7}$. Electron microscopy has shown that the collagen fibers from the involved sites are smaller in diameter and less uniform than normal collagen fibres $^{8}$. Our patient showed the typical clinical manifestation as well as normal radiologic, laboratory and histological findings.

The cause of PDD is unknown. Most cases have no familial link or associated comorbidity. Several authors have suggested that repetitive minor trauma caused by habitual or compulsive habits of interlacing or rubbing of fingers is a cause of PDD ${ }^{2,9,10}$. Similarly, our patient had a habit of repetitively manipulating his hands at times of emotional distress.

The differential diagnoses include knuckle pads, foreign body granuloma, chewing pads, collagenous plaques of the hands, juvenile digital fibromatosis, progressive nodular fibrosis of the skin, thyroid disease, pachydermoperiostosis (Touraine-Solente-Golé syndrome), acromegaly, connective tissue nevi, fibrosing inflammatory conditions, Garrod's pads in violinists, acropachydermodactyly in psoriasis, paraneoplastic acropachydermo- dactyly, Thiemann's disease and sarcomas ${ }^{2}$. In addition, all arthropathies involving the PIP joints should be considered and especially juvenile chronic arthritis and juvenile rheumatoid arthritis.

Because of the benign course of PDD, most patients do not require therapy. However, a case associated with progressive deformation of the affected digits has been reported. Furthermore, some patients want to undergo treatment to rectify the deformity's appearance. Topical treatment with corticosteroids is ineffective. Intralesional injections of steroids often provide good results ${ }^{11}$. Psychological counseling is required for the individuals with compulsive behavior. In selected cases, surgical excision may be an effective cosmetic option ${ }^{12}$. In our case, the patient refused treatment because of the benign characteristics of the disease. He was advised to stop any mechanical skin irritation.

Although PDD is a rare and benign condition, it is important to recognize and diagnose this condition without mistaking it for other conditions that cause soft tissue swelling at the PIP joint. A prompt diagnosis would prevent unnecessary investigations, reassure the patient and avert inappropriate treatment.

\section{REFERENCES}

1. Bazex A, Dupré A, Teillard J. Pachydermie digitale des premières phalanges par hyperplasie conjonctive dermique et aplasie hypodermique. Bull Soc Fr Dermatol Syphiligr 1973;80:455-458.

2. Beltraminelli $H$, Itin P. Pachydermodactyly--just a sign of emotional distress. Eur J Dermatol 2009;19:5-13.

3. Ye S, Chen SL, Dong YQ, Lin F, Guo Q, Bao CD. Pachydermodactyly: six new cases from China. J Clin Rheumatol 2005;11:72-75.

4. Sola A, Vazquez-Doval J, Sola J, Quintanilla E. Pachydermodactyly transgrediens. Int J Dermatol 1992;31:796797.

5. Sandobal C, Kuznietz A, Varizat A, Roverano S, Paira S. Pachydermodactyly: four additional cases. Clin Rheumatol 2007;26:962-964.

6. Taylor-Gjevre R, Saxena A, El Maadawy S, Classen D, Nair B, Gjevre J. A case of deforming pachydermodactyly. J Clin Rheumatol 2009;15:78-80.

7. Kang BD, Hong SH, Kim IH, Kim WK, Oh CH. Two cases of pachydermodactyly. Int J Dermatol 1997;36:768-772.

8. Kim TH, Cho YH, Park HB. Two cases of pachydermodactyly. J Dermatol 1996;23:419-424.

9. Hagedorn M, Graf HG, Grosshans E. Pachydermodactyly. Sequela of obsessive-compulsive neurosis. Hautarzt 1994; 45:88-90.

10. Dupin N, Gautier MS, Rabary G, Auffret N, Beltzer-Garelly E, Binet O. Pachydermodactyly. Ann Dermatol Venereol 1994;121:632-634. 
A Case of Pachydermodactyly

11. Meunier L, Pailler C, Barneon G, Meynadier J. Pachydermodactyly or acquired digital fibromatosis. $\mathrm{Br} J$ Dermatol 1994;131:744-746.
12. Park JH, Lee CW. A case of pachydermodactyly treated by surgical excision. Korean J Dermatol 2006;44:369-371. 